\title{
Social Class and The Unequal Digital Literacies of Youth
}

\author{
RON DARVIN \\ University of British Columbia
}

\begin{abstract}
Recognizing the importance of technology to achieve agentive participation in the knowledge economy, this paper examines to what extent social class differences between youth shape their digital literacies. Drawing on a case study of adolescents of contrasting social positions, it discusses how the material and relational differences of home environments, manifested by spatial configurations, parental involvement and peer networks, can help develop diverse practices and dispositions towards technology. By demonstrating how the inequities of digital use can lead to the unequal accumulation of cultural and social capital, this paper concludes with the educational implications of the third digital divide.
\end{abstract}

Keywords

digital literacy, equity, social class, identity, knowledge economy, capital

\section{Introduction}

Technology in the $21^{\text {st }}$ century has become the fulcrum of the knowledge economy. Not only has it accelerated the transnational flow of ideas, it has also enabled new means of acquiring and transmitting economic, cultural, and social capital. By constructing new forms of labour and modes of productivity, technology has reshaped industries, business processes, and work environments, and increased the demand for knowledge work involving information processing and knowledge creation and distribution (Castells, 2010; Jones \& Hafner, 2012; van Dijk, 2012). To participate in this knowledge economy, learners need to develop digital literacies that will enable them not only to consume and produce knowledge purposefully, but also to curate their identities strategically and maintain meaningful social networks (Norton, 2013). In this context, "knowing" is an intellectual and economic process that relies on language and literacy practices, a capacity for abstract thought, and technological advancement (Farrell, 2009). How learners develop these relevant competencies to navigate the digital landscape has become crucial to achieving social mobility in the new world order.

As a critical factor in generating and accessing power, technology can also lead to "one of the most damaging forms of exclusion" (Castells, 1999, p. 3). While some learners are able to participate fully in technological networks, there are those who remain disconnected or limited to the periphery of participatory cultures (Jenkins, Ito, \& boyd, 2016). To understand this digital divide, scholars have examined issues of access and connectivity (Stevenson, 2009; Vehovar, Sicherl, Hüsing, Dolnicar, 2006) and have more recently expanded to analyses of differences in digital use (Epstein, Nisbet, \& Gillespie, 2011; Smythe \& Breshears, 2017; van Deursen \& van Dijk, 2010). In this broader understanding, fully harnessing the power of technology requires not only access to devices, but also the skills to locate, evaluate, and activate resources available online. As 
schools continue to integrate technology into curricula and pedagogy and recognize the internet as a significant source of knowledge, how learners acquire different digital literacies at home has significant implications in terms of educational equity. Technology use, if unmediated, can result in greater social fragmentation (Darvin, 2016; Facer, 2011; Stromquist, 2002; Warschauer \& Matuchniak, 2010).

To understand how mechanisms of digital inequity can shape the social trajectories of today's learners, this article draws on data from a case study investigating the digital practices of two adolescents from contrasting social positions. Challenging the notion of the "digital native" (Prensky, 2001) that ascribes digital fluency to a generation of users born into technology, it illustrates how young people of different backgrounds can develop diverse sets of digital literacies. By using social class as a lens to examine the material differences of these backgrounds, it dissects how learners possessing varying levels of economic, cultural, and social capital can be socialized into various digital practices. It seeks to answer two questions: (1) How might learners of different social class positions develop diverse digital literacies at home, and (2) How can the material conditions of the lived existence of these learners shape their digital literacies? The contention is that parental involvement, access to digital resources, and peer networks shape the dispositions of learners towards technology as well as their homegrown digital practices. Constructed through and with resources and discourses on hand, these out-of-school digital literacies may or may not align with school expectations and the demands of the knowledge economy-producing outcomes that can privilege some learners while marginalizing others.

\section{Digital Literacies and the "Digital Native"}

As schools experiment with blended and flipped classrooms and continue to incorporate technology in classroom practices, designing an inclusive digital curriculum remains a challenging task. Digital frameworks articulated in educational policies involve ideological assumptions of what constitutes digital literacy, and the ways it can be learned. Within these frameworks, students are often imagined as "roaming autodidacts" (McMillan Cottom, 2017) who are self-motivated, able learners "embedded in technocratic futures and disembedded from place, culture, history, and markets” (p. 214). This essentialized notion of a generation of learners persists despite the fact that Prensky's (2001) construct of “digital natives” has been greatly challenged (Bennett, Maton \& Kervin, 2008; Helsper \& Eynon, 2010; Margaryan \& Littlejohn, \& Vojt, 2011, to name a few). Referring to the generation that grew up with digital technology, Prensky (2001) coined the term "digital natives" to refer to "'native speakers' of the digital language of computers, video games, and the internet” (p. 1). It was a term that achieved currency in both academic and journalistic discourse, constructing the notion that young users are naturally adept in operating digital tools. The idea however that there is one "digital language" out there that users need to master to encode and decode meaning is greatly limited. It essentializes age as the single and most important determinant of "digital fluency" (Hsi, 2007; Miller \& Bartlett, 2012), even though there is scant evidence to support the existence of a homogenous generation with technical expertise and a distinctive learning style (Bennett et al., 2008).

While the construct of the digital native has been challenged, schools and ministries often view digital literacy as a uniform set of skills, with clear stages of development that 
apply to all students. The Ministry of Education in British Columbia (BC Ministry of Education, 2017), for instance, defines digital literacy as "the interest, attitude, and ability of individuals to appropriately use digital technology and communication tools to access, manage, integrate, analyze, and evaluate information, construct new knowledge, create and communicate with others" (p. 1). Although this definition points out that performing digital tasks does involve "interest" and "attitude," it asserts digital literacy as a singular "ability." In the same vein, the British Columbia Digital Literacy Framework, based on the National Educations Technology Standards for Students (NETSS) developed by the International Society for Technology in Education (ISTE), breaks down this ability into six components: (1) research and information literacy; (2) critical thinking, problem solving and decision making; (3) creativity and innovation; (4) digital citizenship; (5) communication and collaboration; and (6) technology operations and concepts. Reflected in this conceptualization is an autonomous view of digital literacy (Heath \& Street, 2008) that regards it as a neutral or technical skill operating in a general manner regardless of local configurations. School district digital policies often adopt this autonomous model, ignoring social class differences that impinge on the access of learners to various resources.

Recognizing how digital engagement involves diverse contexts and practices, this paper uses the plural "digital literacies" to refer to the fact that specific circumstances and material conditions require users to adapt the affordances and constraints of digital tools in multiple ways. In this sense, users assemble various technical possibilities available to them in order to achieve specific purposes. Jones and Hafner (2012) argue that when one engages with the digital, one is establishing relationships and enacting multiple identities, and thus there are different practices of thinking, communicating, and relating through digital media. Ito and others (2010) have categorized the digital practices of youth by examining their different motivations, and identifying genres of participation with new media that reflect youth culture, social network structure, and modes of learning. Friendship-driven practices are dominant and mainstream practices that involve everyday negotiations with friends and peers in one's local social worlds. Instant messaging, social network sites, and mobile phones become ways to negotiate these friendships. Youth look to their peers for affiliation and competition, and digital practices become a form of socialization - the equivalent of hanging out. Interest-driven practices, on the other hand, are those where learners engage with a different network of peers, participating in specialized activities that revolve around particular interests. By focusing on topics of interest, hobbies, and career aspirations, these practices involve communicating, exploring, and extending understanding that allows participants to collaborate with people of diverse ages and backgrounds.

\section{Social Class and Inequities of Digital Access and Use}

In contrast to an autonomous model, an ideological model of digital literacy (Heath \& Street, 2008; Warschauer, 2009) recognizes the "differentiated, situated, and enculturated ways in which digital practices happen” (Snyder \& Prinsloo, 2007, p. 173). Technology use is always positioned not just in a particular classroom, school, or pedagogy, but also within the social and cultural conditions of out-of-school contexts (North, Snyder, \& Bulfin, 2008; Prinsloo \& Rowsell, 2012; Snyder \& Prinsloo, 2007). The differences of digital access and use in these multiple spaces construct two levels of the digital divide (Selwyn, 2004); for Ragnedda (2017), how online experiences influence 
people's social trajectories in the offline world constitutes a third. Users who are able to navigate the Internet with greater flexibility and versatility stand to gain socially valuable resources, overtaking those who are not able to develop this strategic competence. In the knowledge economy, it is the speed at which one is able to gain information that constructs the gap between the "information rich" and the "information poor." This knowledge gap, first theorized by Tichenor, Donohue, and Olien (1970), suggests that as media information in a social system increases, those with higher socioeconomic status tend to acquire information at a faster rate than their lower status counterparts.

To understand further the processes of these digital inequities, this paper uses social class as a construct to understand the contrasting social positions of digital learners. An under-researched construct in language and literacy studies (Block, 2012), social class has often been employed as a corollary inscription of identity with subjects identified as "White middle-class male" or "Black working-class woman" to reflect positions of privilege or marginalization. Studies that do examine class more purposefully often rely on geographical locations, neighbourhoods, immigration categories, or ethnolinguistic identities to identify socioeconomic status (SES) (Garnett, Adamuti-Trache, \& Ungerleider, 2008; Toohey \& Derwing, 2008; Valdes, 1998)—a measure based on income, education, and occupation. This paper asserts however that understanding the unequal positions of learners through this primarily economic indicator is limited. While traditional models of social stratification by Marx, Weber, and Goldthorpe fail to reflect the new world order, current theorization of social class recognizes that it is also a cultural process, marked by consumption patterns, identity formations, and bodily performance (Block, 2012, 2014; Kelly, 2012; Savage et al., 2013). Social class reflects relationships between economic and cultural inputs, which are best integrated by Bourdieu's conceptualization of social class built on the constructs of habitus, field, and capital.

For Bourdieu (1990), habitus is "a system of durable, transposable dispositions... principles which generate and organize practices and representations” (p. 53). As a disposition, habitus is both structured and structuring; it is an organized system of what is deemed reasonable or possible, shaped by one's history and social position; and it is a tendency to perceive and perform things in ways that correspond to these structures. What people judge and internalize as reasonable comes from habitus, acquired by real structures of social advantage and disadvantage, and constituted by combinations of capital. Capital is power in its different forms: economic capital refers to wealth, property, and income; cultural capital is knowledge, educational credentials, and appreciation of specific cultural forms; and social capital is connections to networks of power (Bourdieu, 1986). These forms of capital are circulated and competed for in arenas of struggle or structured spaces called fields. As people struggle for position within fields and enact different social practices, commonalities surface, and people unconsciously align themselves with those with whom they share similar dispositions and tastes. A dominant class determines what is valued in a field and transforms it into symbolic capital (Bourdieu, 1987).

The knowledge and skills that allow learners to operate with a degree of competence become symbolic capital when they are recognized and valued within a specific field. Hence, if digital practices learned at home mirror those valued in school, learners are able to acquire symbolic capital in the field of education (Bourdieu \& Passeron, 1990). Drawing on Bourdieu's theoretical toolkit, Selwyn (2004) identifies how different forms of capital can be transformed into technological capital. Economic capital enables 
the purchase of hardware and software, and other material exchanges and resourcing. Cultural capital involves both participation in digital learning contexts and socialization into technology use. Social capital involves family, peers, tutors, and others who comprise their technological network. Studies have shown (Warschauer, 2007; Warschauer \& Matuchniak, 2010) that computer mastery usually depends on support from peers and family members, and that low-income or immigrant youth tend to have fewer friends or relatives who are sophisticated users of digital media, while more privileged learners are more likely to have mentors at home to guide them. Employing a Bourdieusian framework, North, Snyder and Bulfin (2008) have put forward the idea of "digital tastes" which they define as preferences for technology use. They assert that the home socializes learners into understanding, accepting or rejecting digital practices, and this socialization involves the appropriation of technology to fit existing family norms, values, and lifestyles. The level of education, occupation, and geographic location of parents shape their dispositions regarding digital practices (North, Snyder, \& Bulfin, 2008). Whereas some families value technology for consumption of information, those who are not directed towards traditional academic success may view new media and technologies as entertainment tools. As young people make technologies their own, their different life circumstances shape beliefs and expectations regarding technology (Kvasny, 2006).

In an earlier study of social media usage in the U.S., Boyd (2009) observed that teenagers from different class backgrounds were engaging with social media in fundamentally different ways. Middle-class users, she noted, were more likely to choose Facebook over MySpace because of design and functionality, while more working-class users remained in the latter, which began to develop a reputation for being sexualized and "ghetto." She pointed out that teenagers from wealthier, more educated backgrounds would choose to participate in online environments popular with adults rather than those preferred by youth of less privileged backgrounds. In this case, the contrasting digital tastes of users ushered them into separate online environments, and patterns of social media adoption reflected existing social stratification.

Undertaking an ethnographic study of the digital practices of children from contrasting social positions in South Africa, Lemphane and Prinsloo (2014) demonstrate how differences in digital access and use of the participants not only afforded different means of representation, but also enabled different imagined identities, investments, and ambitions. With access to a desktop and a PlayStation and unlimited broadband connectivity, the middle-class children were able to gain access to more English-language resources, allowing them to develop topic-specific vocabulary and meta-awareness of language. By adapting avatars, they were able to experiment with different accents and become familiar with global middle-class cultural references, while developing classspecific dispositions. The working-class children, on the other hand, had only mobile phone access, and the games they were able to play on these devices provided no language development opportunities. They spoke mostly a colloquial version of the local language, indexical of their working-class status and not valued in school. In this context, the contrasting digital practices led to different resources, tacit knowledge, and habits that may or may not be bridged to school literacies and classroom practices.

These studies demonstrate how class positions can shape digital practices and tastes, which in turn can determine opportunities for language use. How these studies operationalize the construct of class range from finding patterns of use within class 
groupings (i.e., middle class versus working class) to demonstrating how class-inscribed conditions (i.e., access to different resources) can shape practices. Employing a Bourdieusian conception of class, this paper aligns with the latter by examining how different levels of economic, cultural, and social capital, manifested in the material conditions of learners' lifeworlds and their social relations, can shape diverse digital practices and dispositions towards technology. It recognizes that while habitus may predispose learners into certain attitudes or actions, it does not singlehandedly determine them. Learners of different social positions have the capacity to imagine agentive possibilities that can transgress the predispositions of their habitus. At the same time, understanding how different forms of capital operate can help them strategize how resources on hand can be used to gain new capital.

\section{Ayrton and John: A Case Study}

The data used in this article is derived from a pilot case study conducted by the author in Vancouver, British Columbia, Canada in 2013 to compare the language and literacy practices of two 16-year-old Filipino immigrants of contrasting social class positions. By examining the class-inscribed worlds of two adolescents, this study responds to Selwyn's (2012) call "to develop socially-grounded understandings of the realities of education and technology 'as it happens"” (p. 219) and to illumine how the integration of technology into education necessitates a greater understanding of these class differences. Gaining access to the homes of these participants allowed the researcher to observe firsthand the material conditions of their lived existence, their relationships and interactions with family members, and the natural habitat in which they engage with their own devices. Through an approach that combines interviews and observations, the researcher was able to gain access to the participants' own perception and understanding of their digital practices, while comparing them with the actual enactment of these practices. While the study is limited because it did not involve observations in school, the analysis of how the participants' digital practices are shaped by their material interactions with humans and devices provides insight into the class-inscribed experiences of other immigrant youth.

An under-examined group in educational research, Filipinos are the third largest visible minority in Vancouver after Chinese and South Asians. What makes Filipinos a particularly interesting case for an examination of social class is that while they have the highest educational attainment and employment rate in Canada (Ysaad, 2012), they are also the most proletarianized - that is, they are among the largest percentage of working class, at $70 \%$, and among the smallest percentage of petty bourgeoisie and employers, at $4 \%$ (Satzewich \& Liodakis, 2013). That Filipinos are easily absorbed into the Canadian workforce has been attributed to the fact that English is the medium of instruction in the Philippines, a former colony of the United States (Yssaad, 2012). Despite this linguistic and cultural affinity, studies of Generation 1.5 students in Canada have shown that Filipino youth have lower grade point averages than youth in other groups, and have a lower likelihood of graduating from high school (Farrales, 2011; Gunderson, 2007; Toohey \& Derwing, 2008). A study of Filipino secondary school students in east Vancouver describe them as "quietly drift[ing] off," as a third of them appear to be dropping out of high school (Farrales \& Pratt, 2012). By focusing on Filipino immigrant learners, this study sought to understand how relationships with technology might contribute to this trend. At the same time, by choosing Filipinos of contrasting class positions, the study tried to demonstrate 
how, within ethnicities, there is a class hierarchy, and that ultimately class differences are what shape digital inequities.

The two focal participants were personally invited by the researcher to be part of this study. Ayrton is the youngest son of the researcher's family friend, while John was recommended by a colleague. Home visits were conducted when there were other adults (a parent or older sibling) present. The initial interview was designed to help participants familiarize themselves with the interview process, and to collect data regarding their class backgrounds. The succeeding interview focused on investigating their digital practices, which the participants demonstrated with their own devices. After the second interview, the researcher reflected on what other aspects of their digital practices needed further elaboration. These gaps were addressed in the final home visit, where participants were asked to perform whatever digital tasks they had scheduled that afternoon. Through this series of interviews, the researcher collected photos of literacy artifacts (such as books and screenshots of digital texts consumed and produced by the participants, including social media) and eight hours of interview recordings. The semi-structured interviews were initiated in English, although participants were given the option to respond and pursue the interview in Filipino, English, or a combination of both. Both participants however chose to speak only in English throughout the research process. Transcripts of the interviews were represented for general readability and do not include silences, false starts, intonational contours, or similar interactional features, nor do they indicate subtle distinctions between sounds. Ayrton and John are pseudonyms chosen by the participants themselves. While most of the data here are presented for the first time, some have been published in earlier work examining social class and migrant students (Darvin \& Norton, 2014) and English as a lingua franca (Darvin, 2017).

\section{Class Differences of Home}

\section{Findings}

Ayrton.16-year old Filipino Ayrton is a tenth-grade student at a private high school. His family immigrated three years before through the Investor class, which is a Canadian immigration category designed to attract experienced business people who have a net worth of at least $\mathrm{C} \$ 1.6 \mathrm{M}$ and which requires an investment of $\mathrm{C} \$ 800,000$ in the country (Citizenship and Immigration Canada, 2012). Ayrton's father continues to own multiple businesses in Manila and makes frequent trips to the Philippines to manage them, while his mother is a homemaker. An older sister is a university graduate who edits films and videos on her computer while an older brother studies mechanical engineering at a prominent university. The family owns an SUV and a Rolls Royce and lives in a three-bedroom unit in a high-rise condominium downtown, a privileged asset in Vancouver's expensive real estate market. Ayrton shares a room with his brother and his shelves are filled with issues of car magazines and the Harvard Business Review that he subscribes to. The language they speak at home is primarily English, which was also the case when they were living in a two-storey house with a swimming pool in a gated community in the Philippines.

Before relocating to Canada, Ayrton's mother actively researched online to find the ideal private school for him, and he was accepted after a Skype interview with the school's admissions committee. At this school (where students of privileged backgrounds are enrolled), Ayrton takes a business elective and is also part of an outdoor program where selected students pay an extra fee to engage in a yearlong set of activities. (These activities 
include traveling to different parts of Canada, as well as camping, hiking, and learning how to ski and snowboard.) Because of his interest in currency trading, Ayrton (with the support of his parents) also registered for Infinite Prosperity, an e-learning course, which provides him with the information and analytical tools necessary to become a trader in the future. To manage his businesses effectively, Ayrton's father keeps up-to-date with current events and business trends by reading the news online or listening to the radio. A university graduate who studied Spanish and an avid reader, Ayrton's mother taught herself French to be able to tutor him in the language. When it comes to Math or questions about the computer, Ayrton relies on his brother. Everyone in the family has their own laptop, with the exception of Ayrton's mother, who uses a desktop in a study room shared by the family. Ayrton owns a laptop, an iPad, and a Samsung phone. The computers are networked to a printer and a scanner, and all family members have their own computer-dedicated spaces.

John. Like Ayrton, John is also 16 but is a Grade 11 student at a public school in East Vancouver. He moved to Canada when he was ten, after six years of being separated from his mother who started working in the country as a caregiver under temporary migrant worker arrangements. After years of negotiating the immigration requirements, she was finally able to bring John and his older sister to Canada through the Family immigration class, which allows migrant workers to become landed immigrants with their immediate family members. John's father, who is legally separated from his mother, continues to live in the Philippines. John, his mother, sister and 6-year old brother rent a one-bedroom apartment in a three-story building. They speak primarily Filipino at home. John shared that, at first, he was not happy about living in Canada. In the Philippines he had more freedom, playing with his cousins and neighborhood friends out in the streets after school. Because they had household helpers, he did not need to do any chores. In Canada, he says the possibilities for hanging out with friends are limited. He has to babysit his brother, help clean the house, and take out the garbage. John's sister is studying to be a licensed practical nurse in a community college and supports her education by working part-time. John's mother who studied midwifery in the Philippines continues to work as a caregiver in a senior care facility. Her shifts include weekends, and she usually gets home from work sometime past eleven in the evening. Because his mother and sister are always at work or at school, John is usually expected to fetch his younger brother from school and take care of him at home.

At school, John is enrolled in a computer-programming elective, which he believes will prepare him for studying computer science in college. He enjoys Math and Science, but finds English particularly challenging, and attends ESL classes. John loves anime and recently learned to sketch anime characters. He joined the manga club in school and also taught himself to speak a bit of Japanese. At home, the entire household shares one desktop, which is positioned between the dining room and the living room, right beside the TV. They have two iPads, one of which is used solely by John, who also has his own mobile phone. When his sister needs to use the computer, John walks five blocks to the public library and uses the computer there. Because the apartment is relatively small, there is hardly any private space. In one particular interview session when all family members were at home, I interviewed John by the computer, while the others occupied the dining area and the living room. Because everyone was within earshot, in some instances the mother and the sister would respond to the questions I directed to John. 


\section{Contrasting Dispositions Towards Technology}

Both John and Ayrton are visibly very adept with technology, and multitask with great ease. They can jump from one application to another as they talk about their interests and digital practices. Ayrton clicks swiftly on hyperlinks to get to a desired page and lists URLs from memory. John types swiftly without even looking once at the keyboard, which rests on an unmovable compartment under a tabletop and remains hidden from his view. Both say there have been occasions where their teachers ask them for help with operating the digital projectors or navigating through PowerPoint. When I asked John how he feels about his teachers asking for his assistance, John replied, "it's just usual” because "our generation is more into technology," reproducing discourses of the digital native. Both John and Ayrton demonstrate confidence in their abilities to use technology, and view this ability as natural and undifferentiated. From the observations and interviews, what emerges though are striking differences when it comes to their views of what technology is for, and how they use it at home.

For Ayrton, whose university-schooled family members use technology for researching, managing businesses, and editing films, technology is a source of knowledge and a tool for social mobility. "With how the world is just connected and how information is at your fingertips, you can be anyone or anything you want to be and it's just right there (Interview with Ayrton, October 2013, quoted in Darvin \& Norton, 2015, p. 115). Reflecting the lived reality to which he has been socialized, his class habitus allows him to recognize the immediacy of knowledge ("how information is at your fingertips") and grants him a powerful sense of agency. Social futures and identities ("you can be anyone or anything you want to be) are imagined and realized through the access and use of information. He recognizes the significance of technology ("the world of computers today") and connectivity ("how the world is just connected") in the contemporary landscape, and recognizes how its significance in both school and non-school contexts.

Because of how school and everything is just structured nowadays, it's as if you need to spend that much time in front of the screen or else or you're gonna be left behind or you're gonna miss out on something important. (Interview with Ayrton, October 2013)

For Ayrton, technology is an integral part of education, one that "structures" school and other domains of life, and therefore requires urgent participation ("or you're gonna miss out on something important”). The computer screen is seen as the material gateway to global flows of information that enable greater social mobility ("or you're gonna be left behind").

While Ayrton values technology as a source of knowledge, John views the computer as a tool primarily for games. Any question about how he uses his devices immediately defaults into an excited discussion of Minecraft or League of Legends. "After school I go home and sometimes they ask me to do my work but it's hard for me because I always pay attention to the computer" (Interview with John, October, 2013). From his perspective, the computer is a distraction, one that takes him away from rather helps him with his schoolwork. When steered towards discussing its educational uses, he provides a brief answer. 
Ron: How about stuff for school? What do you use the computer for?

John: Basically for printing (Interview with John, November, 2013)

He talks about how he occasionally writes reports and notes from school then prints it out, but does not mention anything about using the computer for research. This limited function is consistent with his observation of how computers are used in his school, which he says are for "printing and attendance." When asked about how his sister uses their shared desktop, he says, "she only goes to the computer to print something or look at something." While Ayrton recognizes the infinite virtual spaces he can connect to through the computer, John appears to focus on the fixed, physical output that it can provide, that is, through printing.

This disposition towards technology reflects the early digital practices he was accustomed to when he was a young boy studying in the Philippines. In his old school, computer class only involved learning how to use the keyboard. Because his family didn't own a computer then, he would go to the arcade or Internet cafes to play games. Although they now own multiple devices in Canada, home usage still appears to be more geared towards entertainment. As a busy caregiver, John's mother hardly has any time to use the computer, and if she does, she says she uses it to do Facebook, and to watch her soap operas. Her preference to use technology for entertainment purposes indexes the material conditions of her social position-as a caregiver whose work does not require the use of technology, as the sole breadwinner whose busy schedule limits opportunities to use technology and expand her digital repertoires, and as an immigrant who seeks to maintain social and cultural ties with family and friends in her home country. Focused on entertainment and relational purposes, this mode of use is reflected in John's own preferences.

\section{Digital Practices and the Reproduction of Capital}

Shaped by the digital practices they observe at home, the contrasting dispositions towards technology of Ayrton and John structure their own engagement with technology. On a school night, Ayrton spends around four to five hours at the computer, and more than half of that time is spent on schoolwork. The rest of the time is to monitor currency trends, fill out his currency trading journal, read up about cars, and scroll through his Facebook newsfeed. Because he gets busy with schoolwork, he rarely gets a chance to play games, sometimes going without games for several weeks. He and his family have dinner together, and this shared family time provides a break from being in front of the computer the whole evening. He also shares the bedroom with his older brother, and so the length of time he spends with the desktop is shaped by negotiated bedtimes. In contrast, John gets home at 3:30 PM to a usually empty house and goes straight to the computer, while his younger brother tinkers with the iPad. With his mother at work the entire evening, John has to microwave dinner for his brother and himself, and he usually eats it in front of the computer.

Ron: When you get home... what do you do?

John: Games.

Ron: So games until around... what? 
John: 9. 10.

Sister: Until he gets tired...

Mother: Sometimes I come home from work, he's still there. 11:30. (Interview with John, November, 2013)

Because his mother, sister, and brother occupy the one bedroom of the apartment, John sleeps on the couch, right beside the computer, allowing him access to it even when everyone else is asleep. Most of John's evening is spent playing two of his favorite games. Minecraft is a game where a player gathers resources like wood and stone to craft tools, weapons and buildings. In League of Legends, a team of players or "champions" work together to destroy the opposing teams" "nexus" or base. John describes it as a "game of strategy" where teams plan together which role each member would take, depending on the powers of the enemy team. John plays this with his school friends who are online at the same time, and they plan and execute their mode of attack by communicating via Skype. Because these friends are also Filipino immigrants, they speak in Filipino. The champion or avatar can be purchased either with real money or "in-game" - that is, by earning credits by winning games. A champion bought with real money is more powerful and better animated, but John shares that "one champion is like ten bucks, which is really expensive" (Interview with John, November 2013). Because he would like to acquire new champions, John then has to spend more time playing so that he could win and earn credits.

John is obviously very passionate about gaming, and demonstrates greater fluency in English when he talks about his favorite games, an indication of his total immersion in this form of entertainment. His Facebook activity, on the other hand, reflects his passion for anime. On his profile, he has written his name in Japanese and his cover photo is from Death Note, a popular anime TV series from Japan (See Figure 1).

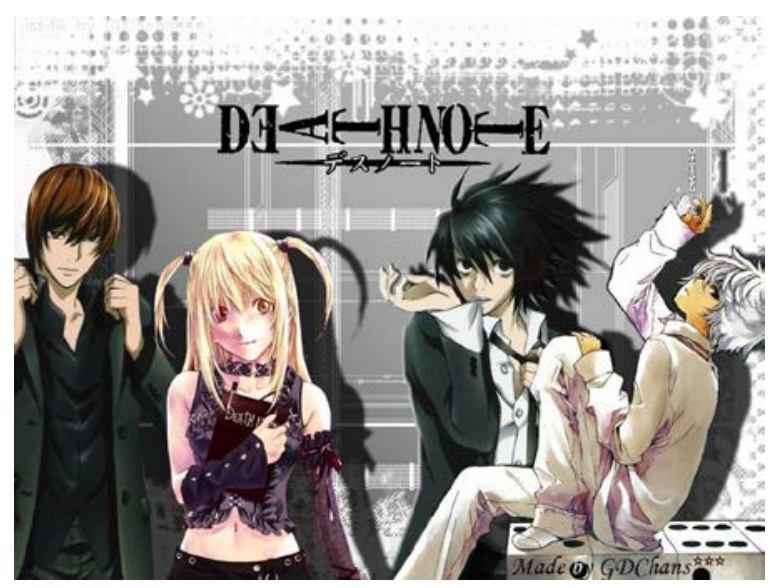

Figure 1. John's Facebook cover photo.

This image is a wallpaper jpeg that can be downloaded for free, and indexes his youth. Most of the pictures he has uploaded are his anime sketches of girls in very provocative poses, not unlike the girl in this photo. He has "liked" a great number of anime pages, which means he gets multiple updates about anime on his newsfeed, and these updates are mostly images with a brief caption. Other pages he has liked (there are more than a thousand) are pages of celebrities or sports teams. 
Reflecting his passion for cars, Ayrton's cover photo on Facebook is the engine of a Pagani Huayra, a sports car (See Figure 2) at an auto show in Vancouver that he attended.

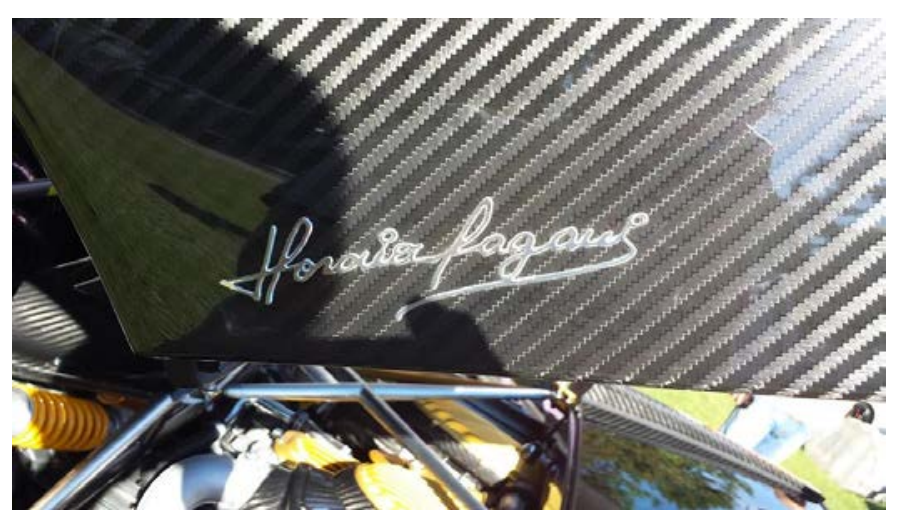

Figure 2. Ayrton's Facebook cover photo.

He has liked a number of car pages and because of this he gets a lot of updates on his news feed that lead him to feature articles about new models of cars. While John's cover photo indexes his youth, Ayrton's positions him as a car enthusiast who has the economic resources to participate in activities like car shows and the cultural capital to participate in these discourses. He also is part of the Infinite Prosperity Trading group on Facebook, which serves as a forum for those who are registered in Ayrton's e-learning course. On this page, they exchange tips, pose questions, and share relevant articles. For Ayrton, Facebook is not just a platform to interact with friends, but also a way to gain knowledge and expand his social network. It becomes an aggregate of information on topics he is interested in. This valuing of information is also reflected in the way he uses his phone. Apart from using his mobile phone to text and check email, Ayrton uses it to read the news in between classes. It contains a BBC app that he has installed "to have a general idea of what's going on." He also downloaded a CNN app "to see different perspectives of how the news is being reported" - an indication of how he has adopted critical media literacy skills.

Ayrton demonstrates not only fluency in English in whatever topic he is discussing, but also remarkable literacy skills, having published a 150,000-word story in a fan fiction site. Comprised of 18 chapters, his serialized novel is a crossover of Eric Nyulund's Hero novels and the animated TV series My Little Pony: Friendship is Magic. Although targeting a demographic of young girls, My Little Pony has also attracted a large fan base of adult males who call themselves "bronies" and Ayrton is part of several "brony" groups on Facebook. Published in installments for almost two years, Ayrton's novel received more than 1,100 likes and more than one thousand comments, many of which complimented his writing skills. Some even mentioned that it was one of the best stories they've read in a long time. When Ayrton decided to write for the fan fiction page, he submitted a sample of his work to an online board of editors. Someone took interest and agreed to be his informal mentor, offering him feedback on his work before he published each chapter. Ayrton's interest in My Little Pony is also reflected in his Facebook page. His profile picture is a plushy of Vinyl Scratch, a DJ from the My Little Pony, to which he has attached headphones (See Figure 3). He says he chose this image to represent himself because he shares an interest in electronic music with the character. 


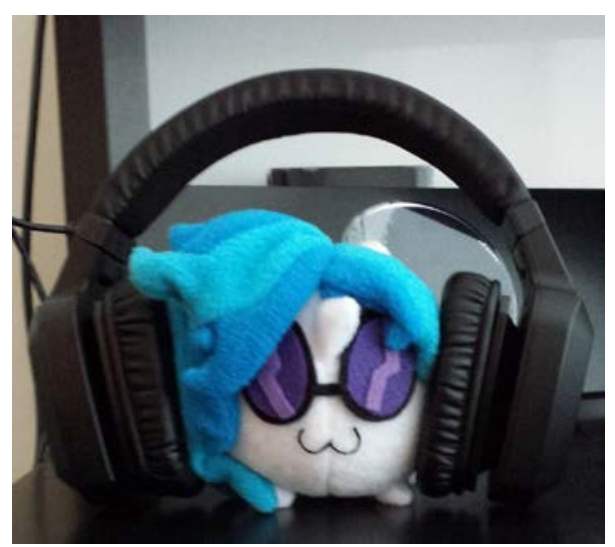

Figure 3. Ayrton's Facebook profile photo.

Unlike John, who uses a candid picture of himself for his profile photo, Ayrton chooses to assemble objects together and imbue them with symbolic meaning. By using a profile photo that does not reveal his age, Ayrton is also able to interact with professionals in the Infinite Prosperity Facebook forum without them knowing that he is in high school. Because John is preoccupied with playing games, he is not particularly active in producing digital texts. His hobby is sketching anime images, which he either copies from comic books or draws from his imagination. He uploads pictures of these creations on Facebook (See Figure 4), but he receives only one or two likes at a time.

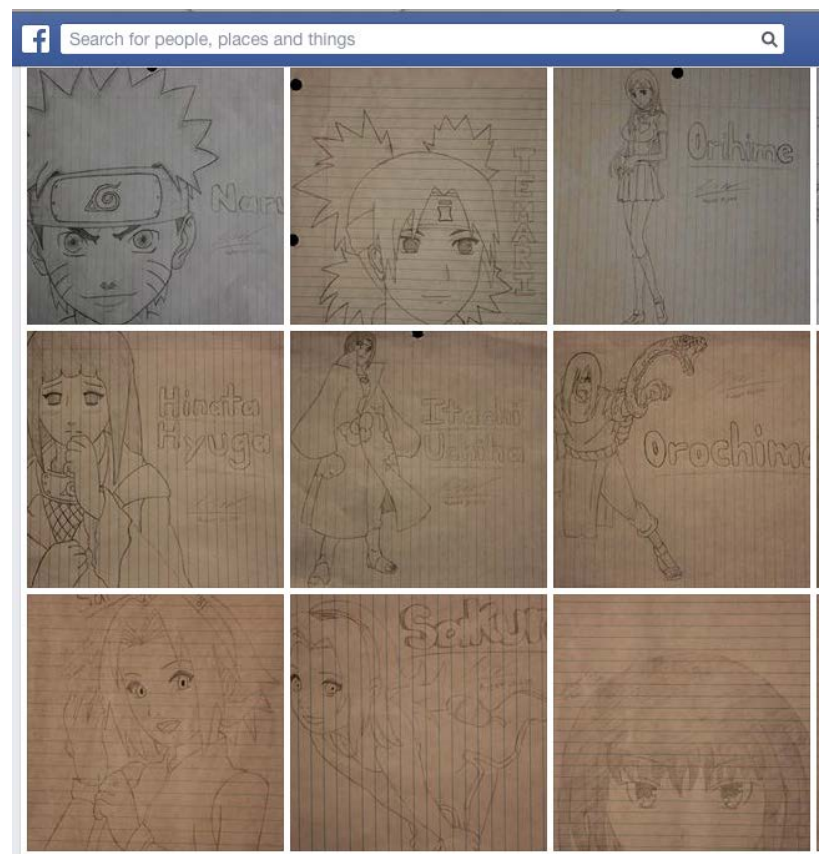

Figure 4. John's anime sketches on Facebook.

Unlike Ayrton's digital production of an online fan fiction novel read by hundreds of people, John's sketches are viewed only by his limited number of friends on Facebook. While they are uploaded onto an online platform, they are digital copies of print texts that to not enable him to develop digital design skills. He has attempted using Paint to draw 
manga images, but finds it difficult to control the mouse. Paid animation applications, he says, "have more colors, more different kinds of tools where you can change the animation" (Interview with John, November 2013) but he is only able to download free versions, which have limited functionality.

\section{The Construction of Identities and Networks Online}

As these two learners navigate the digital world with contrasting habitus and forms of capital, they not only develop diverse digital practices, but also construct their identities and networks in different ways. Because Ayrton interacts with interest groups like currency traders or bronies, and produces digital texts that are shared with a broad fan base, he is able to engage in productive discussion with editors, fellow fans, and professionals from a global network. He is able to develop his writing skills, gain greater knowledge about economic trends and transactions, and receive affirmation for his work and insights. Not surprisingly, the skills that Ayrton acquires align with practices valued in the knowledge economy-creating and circulating information, expanding social networks, and curating online identities (Castells, 2010; Jones \& Hafner, 2012; van Dijk, 2012).

"Technology has been that bridge... that connects me to people as far as Orlando in the United States or people back in the Philippines” (Interview with Ayrton, October, 2013). In this statement, Ayrton expresses how the digital enables him to maintain transnational ties with people, and build relationships in a more global context. He links this affordance to his own migration experience by explaining how, living in a privileged and very protected environment in the Philippines, his life revolved around home, school, and neighborhood. "Moving [to Canada], I had to get out of that isolated world," he says. As part of his private school's outdoor activity program, he is able to discover new places in Canada and forge stronger friendships with a multicultural set of similarly privileged friends. The combination of migration and technology allows Ayrton to cross real and virtual borders and experience new worlds.

While Ayrton's migration involved expanding his world with his family intact, John's migration unfolded under different class conditions and appears to have led to greater isolation. Separated from his mother for more than six years, John grew up with his father, grandmother, and cousins. Migrating to Canada meant giving up that family, the freedom to wander in spaces he was familiar with, and the comfort of having others do household chores. "Before, I always went outside and play. Here, kind of less." In the Philippines, he would go to the arcade with his friends, but now that he has a computer, he plays these games at home. Motivated by his own social needs, his participation in games is largely friendship driven, and because of responsibilities at home and the costs of hanging out elsewhere, the screen has replaced the playground. By interacting online with people he already knows, he maintains a network that is limited to friends from school. He develops skills in strategizing game plans, but does not gain information that is considered cultural capital in school settings, nor is he able gain opportunities to speak English and gain linguistic capital in his country of settlement. Playing League of Legends and using Skype with his predominantly Filipino friends, he is able to build social ties in Canada, although with a network that is more limited than Ayrton's.

Not only are Ayrton's and John's digital practices different, but because of their contrasting dispositions towards technology, how they use the same platform can lead them to different content. Because John views technology as primarily a source of entertainment, 
his digital engagement reflects this view. When asked about what he watches on YouTube, John says, "Funny videos.”

Ron: Usually what kind of funny videos do you like?

John: Prank call.

Ron: Prank call? Okay. What is it? Can you tell me?

John: Mmm. A person like, ah, takes a video and calls on the phone-for example, he calls on McDonald's and, like, afterwards he says, "Oh is this the hospital?" (Interview with John, November 2013)

In contrast, when Ayrton talks about YouTube, he expresses how it allows him to gain knowledge and motivation to do different things. He describes a video featuring a young currency trader who earned a huge profit, and was able to buy one of his favorite sports cars. Watching this story, he says, motivated him to imagine a future for himself.

I just got to learn how they do this. I want to be like them. So I enrolled in the course during the summer, learned how to become a currency trader, and I have to say it was one of the greatest investments of my life. And it was all-now that I think of it-all because I came by one video of a 22-year-old girl buy a Lamborghini and an Audi. (Interview with Ayrton, October, 2013)

Because his digital practices are driven by an interest to gain knowledge, Ayrton was able to imbue a YouTube video with symbolic meaning that one might less likely be able to do with a "Prank Call" video. People who share his interest in cars become role models who allow him to discover a new interest-currency trading. His paradigm of what purpose the digital serves leads him to digital practices and interpretations of digital texts that prepare him for greater social mobility. That he describes enrolling in the e-learning course as "one of the greatest investments of my life" already reflects an entrepreneurial spirit undoubtedly role modeled by his father. Consistent with this outlook, Ayrton's favorite quotation posted on his Facebook is: "Why wait for something to happen when you can make it happen?” Indeed, his digital world allows him to gain a greater sense of agency by claiming ownership of a future that he is able to imagine for himself.

\section{Discussion and Conclusion}

This paper began by asking how learners of different social class positions might develop diverse digital literacies at home, and how the material conditions of their lived existence can shape these digital literacies. What emerged from the findings is that a dynamic interplay of class-inscribed factors shaped the out-of-school literacies of these adolescents. The configuration of physical space, the combination of digital and non-digital resources, and modes of parental engagement constructed home environments that socialized them into specific digital dispositions and practices. In terms of digital resources, the findings highlighted how access to software is as critical as hardware and connectivity. While both Ayrton and John had their own phones and computers, their capacity to buy programs or make in-app purchases also determined their digital practices. Ayrton was able to register for an online course, while John could not afford to purchase animation programs or in-game features. This limitation presented a constraint to his production of 
creative digital work, and not having the economic capital to buy "skins" for League of Legends required him to invest more time in the game so that he could acquire this feature for free.

The findings also demonstrated how parents' engagement with technology was not just a product of educational achievement, but was shaped by the circumstances of their own occupations and life trajectories. How John's mother used technology more as a source of entertainment, for instance, can be attributed to the nature of her work, her limited leisure time, and her desire to maintain transnational ties. Because of her busy schedule as a sole breadwinner, there was not much opportunity to supervise John's digital practices and study habits. Ayrton's parents on the other hand were always available. Managing businesses remotely from a dedicated workspace, his father was able to role model the entrepreneurial and informational affordances of technology. Apart from the material conditions of home, the class habitus of Ayrton and John structured their tastes, interests and sense of agency, which in turn shaped their digital practices. The entrepreneurial spirit imbibed by Ayrton's father motivated the young man to participate in an online currency trading course, allowing him to gain new cultural and social capital. Having traveled and connected with people in distant places, Ayrton was able to position himself as a global citizen who could connect with distant others through technology. John, on the other hand, having migrated through different circumstances, maintained a more localized network. His interest in anime and games did not translate into cultural productions and social interactions that could increase his capital. The contrasting dispositions towards technology of Ayrton and John shaped not only their view of computers (distraction vs. tool; medium of entertainment vs. source of knowledge), but also their ideas of what different platforms are for (YouTube as a source of funny videos versus YouTube as educational or motivational medium).

Corresponding to ideas of the third digital divide, the findings demonstrated how users who are able to navigate the internet with greater flexibility and versatility stand to gain socially valuable resources. How the adolescents negotiated their economic, cultural and social capital helped determine their access to different spaces online, which in turn could generate new capital. By publishing a fan fiction novel online, Ayrton was able to grow his own fan base and meet a semi-professional writer who mentored him. By joining an online course and curating his social media identity, he was able to gain both cultural and social capital that could potentially provide him with economic capital from trade transactions. John, on the other hand, was limited to his Facebook network, and posting pictures of his anime sketches or playing League of Legends for hours every day did not provide him with cultural or social capital that enabled greater social mobility.

The diverse digital practices of Ayrton and John confirm vividly how one cannot ascribe a single, neutral digital competence to these "digital natives." However both Ayrton and John themselves reproduce this discourse of 'native-ness' by referring to themselves as part of a generation that is naturally adept in technology. By accepting this essentialized notion, they may assume that their existing digital literacies already encompass the full extent of technological potential or that these digital literacies are acquired effortlessly. What this paper asserts however is that social class differences manifested in material and symbolic ways shape unequal digital literacies. The material conditions of one's lived existence, one's history and ongoing experiences shape dispositions towards technology 
and digital practices that can reproduce the unequal distribution of economic, cultural, and social capital.

If we look at the components of digital literacy that are valued in the BC curriculum-managing and evaluating information, constructing new knowledge, and thinking critically-Ayrton is already clearly ahead of John, and has access to the resources that these standards require. Because Ayrton's digital practices enable him to gain valued knowledge and expand his social network, he is able to gain greater cultural and social capital that maintains and even strengthens his class position. What does this mean when Ayrton and John go to school and teachers have certain assumptions of what these "digital natives" already know? How do we ensure that learners of different social positions are given equal opportunities to develop valued digital literacies? Identifying which digital literacies matter and understanding how this valuation affects differently resourced learners are critical steps to achieving more equitable learning (Darvin, 2018).

To mitigate Castells' warning that technology can lead to the most damaging forms of exclusion, schools need to gain a better understanding of the class differences of their students and to make sure the design of digital policies and classroom strategies considers these differences. Leveraging the potential of technology in education requires more school-wide planning to determine how to scaffold more systematically the learning of digital literacies across grade levels. In the BC curriculum, the integration of digital competencies into classroom practices is left to the discretion of teachers, and the lack of coordination and accountability processes can leave significant gaps in the learning of these literacies. To avoid such gaps, teachers need more opportunities to collaborate with each other and design cross-curricular tasks that involve researching online. By providing them with the tools to find legitimate sources and discover information more autonomously, students can cultivate a disposition that recognizes technology as a rich source of knowledge. Teachers need more training not just to learn new apps or educational platforms, but to ensure that their own digitally-mediated teaching strategies are transformative rather than substitutive and that they incorporate a broader spectrum of literacies that affirm the diverse digital repertoires of their students.

Recognizing that class differences can shape diverse out-of-school digital literacies, more efforts to bridge home and school literacies also need to be undertaken. Schools may consider programs that develop the digital literacies of parents and mentors through intergenerational learning experiences. Workshops at informal learning spaces like public libraries or community centres can provide students with opportunities to engage with digital applications that they may not have access to at home. By systematically expanding the scope and spaces of digital literacy instruction, the hope is that not only students but also families of different social class backgrounds can develop valued digital literacies. This expanded approach can cultivate dispositions and practices that enable purposeful consumption and production of knowledge, strategic curation of identities, and meaningful construction of social networks - the necessary components of agentive participation in the knowledge economy.

\section{Acknowledgements}

The author acknowledges the generous support of the Vanier Canada Graduate Scholarships Program and The International Research Foundation for English Language Education. 


\section{References}

BC Ministry of Education. (2017). BC's digital literacy framework. Retrieved from http://www2.gov.bc.ca/assets/gov/education/kindergarten-to-grade12/teach/teaching-tools/digital-literacy-framework.pdf

Bennett, S., Maton, K., \& Kervin, L. (2008). The 'digital natives’ debate: A critical review of the evidence. British journal of educational technology, 39(5), 775786.

Block, D. (2012). Class and SLA: Making connections. Language Teaching Research, 16(2), 188-205.

Block, D. (2014). Social class in applied linguistics. Oxon, UK: Routledge.

Bourdieu, P. (1986). The forms of capital. In J. F. Richardson (Ed.), Handbook of theory and research for sociology of education (pp. 241-58). New York, NY: Greenwood Press.

Bourdieu, P. (1987). What makes a social class? On the theoretical and practical existence of groups. Berkeley Journal of Sociology, 32, 1-17.

Bourdieu, P. (1990). The logic of practice. Stanford: Stanford University Press.

Bourdieu, P., \& Passeron, J. C. (1990). Reproduction in education, society and culture. London, UK: Sage.

Boyd, D. (2009). The not-so-hidden politics of class online. Personal democracy forum. Retrieved from http://www.danah.org/papers/talks/PDF2009.html

Castells, M. (1999). Information technology, globalization and social development. United Nations Research Institute for Social Development. Discussion Paper no. 114. Geneva, Switzerland: UNRISD.

Castells, M. (2010). The rise of the network society: The information age: Economy, society, and culture (Vol. 1). Malden, MA: Wiley and Blackwell.

Citizenship and Immigration Canada. (2012). Investors. Retrieved from http://www.cic.gc.ca/english/immigrate/business/investors/index.asp

Darvin, R. (2016). Language and identity in the digital age. In S. Preece (Ed.), Routledge handbook of language and identity, (pp. 523-540). Oxon, UK: Routledge.

Darvin, R. (2017). Social class and the inequality of English speakers in a globalized world. Journal of English as a Lingua Franca, 6(2), 287-311.

Darvin, R. (2018). Digital literacy, language learning, and educational policy in British Columbia. In J. Crandall \& K. Bailey (Eds.), Global perspectives on educational language policies. New York, NY: Routledge.

Darvin, R., \& Norton, B. (2014). Social class, identity, and migrant students. Journal of Language, Identity \& Education, 13(2), 111-117.

Darvin, R., \& Norton, B. (2015). Identity and a model of investment in applied linguistics. Annual Review of Applied Linguistics, 35, 36-56.

Epstein, D., Nisbet, E. C., \& Gillespie, T. (2011). Who's responsible for the digital divide? Public perceptions and policy implications. The Information Society, 27(2), 92-104.

Facer, K. (2011). Learning futures: Education, technology and social change. London, UK: Routledge.

Farrales, M. (2011). Holding spaces: Geographies of Filipino-Canadian students’ educational experiences (Master's thesis). Retrieved from https://circle.ubc.ca/

Farrales, M., \& Pratt, G. (2012). Stalled development of immigrant Filipino youths. 
Metropolis British Columbia Working Paper Series, 10, 1-62.

Farrell, L. (2009). Texting the future: Work, literacies, and economies. In M. Baynham and M. Prinsloo (Eds.), The future of literacy studies (pp. 181 - 198). Hampshire, UK: Palgrave MacMillan.

Garnett, B., Adamuti-Trache, M., \& Ungerleider, C. (2008). The academic mobility of students for whom English is not a first language: The roles of ethnicity, language, and class. Alberta Journal of Educational Research, 54(3), 309-326.

Gunderson, L. (2007). English-only instruction and immigrant students in secondary schools: A critical examination. Mahwah, NJ: Lawrence Erlbaum.

Heath, S. B., \& Street, B. (2008). On ethnography: Approaches to language and literacy research. New York, NY: Teachers College Press.

Helsper, E. J., \& Eynon, R. (2010). Digital natives: Where is the evidence? British educational research journal, 36(3), 503-520.

Hsi, S. (2007). Conceptualizing learning from the everyday activities of digital kids. International Journal of Science Education, 29(12), 1509-1529.

Ito, M., Baumer, S., Bittanti, M., Cody, R., Stephenson, B. H., Horst, H. A., ... \& Perkel, D. (2010). Hanging out, messing around, and geeking out: Kids living and learning with new media. Cambridge: MIT press.

Jenkins, H., Ito, M. \& boyd, d. (2016). Participatory culture in a networked era. Cambridge: Polity Press.

Jones, R. H. \& Hafner, C. A. (2012). Understanding digital literacies: A practical introduction. Oxon, UK: Routledge.

Kelly, P. (2012). Migration, transnationalism and the spaces of class identity. Philippine Studies: Historical and Ethnographic Viewpoints, 60(2), 153-86.

Kvasny, L. (2006). Cultural (re)production of digital inequality in a US community technology initiative. Information, Communication \& Society, 9(2), 160-181.

Lemphane, P. \& Prinsloo, M. (2014). Children’s digital literacy practices in unequal South African settings. Journal of Multilingual and Multicultural Development, 35(7), 738-753.

Margaryan, A., Littlejohn, A., \& Vojt, G. (2011). Are digital natives a myth or reality? University students' use of digital technologies. Computers \& education, 56(2), 429-440.

McMillan Cottom, T. (2017). Black cyberfeminism: Ways forward for intersectionality and digital sociology. In J. Daniels, K. Gregory, \& T. M. Cottom (Eds.), Digital Sociologies (p. 211-232). Bristol, England: Policy Press.

Miller, C., \& Bartlett, J. (2012). 'Digital fluency': Towards young people's critical use of the internet. Journal of Information Literacy, 6(2), 35-55.

North, S., Snyder, I., \& Bulfin, S. (2008). Digital tastes: Social class and young people's technology use. Information, Communication \& Society, 11(7), 895-911.

Norton, B. (2013). Identity and language learning: Extending the conversation. Bristol: Multilingual Matters.

Prensky, M. (2001). Digital natives, digital immigrants part 1. On the Horizon, 9(5), 1-6.

Prinsloo, M., \& Rowsell, J. (2012). Digital literacies as placed resources in the globalised periphery. Language and Education, 26(4), 271-277.

Ragnedda, M. (2017). The third digital divide: A Weberian approach to digital inequalities. Oxon: Routledge. 
Satzewich, V., \& Liodakis, N. (2013). 'Race' and ethnicity in Canada (3 ${ }^{\text {rd }}$ ed.). Don Mills, Ontario Oxford University Press.

Savage, M., Devine, F., Cunningham, N., Taylor, M., Li, Y., Hjellbrekke, J., Le Roux, B., Sam Friedman, S., and Miles, A. (2013). A new model of social class: Findings from the BBC’s Great British Class Survey Experiment. Sociology, 47(2), 219-250.

Selwyn, N. (2004). Reconsidering political and popular understandings of the digital divide. New Media \& Society, 6(3), 341-362.

Selwyn, N. (2012). Ten suggestions for improving academic research in education and technology. Learning, Media and Technology, 37(3), 213-219.

Smythe, S., \& Breshears, S. (2017). Complicating access: Digital inequality and adult learning in a public access computing space. Canadian Journal for the Study of Adult Education, 29(1), 67-81.

Snyder, I., \& Prinsloo, M. (2007). Young people's engagement with digital literacies in marginal contexts in a globalised world. Language and Education, 21(3), 171179.

Stevenson, S. (2009). Digital divide: A discursive move away from the real inequities. The Information Society, 25(1), 1-22.

Stromquist, N. P. (2002). Education in a globalizated world: The connectivity of economic power, technology, and knowledge. Oxford, UK: Rowman \& Littlefield.

Tichenor, P. J., Donohue, G. A., \& Olien, C. N. (1970). Mass media flow and differential growth in knowledge. Public opinion quarterly, 34(2), 159-170.

Toohey, K., \& Derwing, T. M. (2008). Hidden losses: How demographics can encourage incorrect assumptions about ESL high school students' success. Alberta Journal of Educational Research, 54(2), 178-193.

Valdes, G. (1998). The world outside and inside schools: Language and immigrant children. Educational Researcher, 27(6), 4-18.

van Deursen, A., \& van Dijk, J. (2010). Internet skills and the digital divide. New Media \& Society, 13(6), 893-911.

van Dijk, J. (2012). The network society ( ${ }^{\text {rd }}$ ed.). London, UK: Sage.

Vehovar, V., Sicherl, P., Hüsing, T., \& Dolnicar, V. (2006). Methodological challenges of digital divide measurements. The Information Society, 22(5), 279-290.

Warschauer, M. (2007). The paradoxical future of digital learning. Learning Inquiry, 1(1), 41-49.

Warschauer, M. (2009). Digital literacy studies: Progress and prospects. In M. Baynham and M. Prinsloo (Eds.), The future of literacy studies, 123-140. London, UK: Palgrave Macmillan.

Warschauer, M., \& Matuchniak, T. (2010). New technology and digital worlds: Analyzing evidence of equity in access, use, and outcomes. Review of Research in Education, 34(1), 179-225.

Yssaad, L. (2012). The Canadian immigrant labour market. Statistics Canada. Retrieved from http://www.statcan.gc.ca/pub/71-606-x/71-606-x2012006-eng.pdf 